\title{
A Brief Analysis of Enterprise Social Cost Accounting Confirmation and Measurement*
}

\author{
Xuemei Chen \\ International Business School \\ Shaanxi Normal University \\ Xi'an, China
}

\begin{abstract}
When an enterprise wants to bear social responsibility, it is necessary to spend the corresponding expenditure, and this part of the expenditure is the social costs of enterprises. On the one hand, the existence of social costs of enterprises which have the same technology and products of different enterprises have a difference in social costs, this difference determines the differences in competitiveness of enterprises, for the production and operation of enterprises in the process of social costs necessary. On the other hand, enterprises in the pursuit of their own benefits and at the same time, should also ensure that its commitment to the corresponding social responsibility. However, for a long time, in the evaluation of enterprise efficiency, China's emphasis on economic efficiency and neglect of social benefits, or because of the lack of evaluation system cannot be evaluated. On the one hand, the enterprise social cost is not standardized to confirm the method, it is difficult to measure. On the other hand, the corporate social responsibility is limited, the enterprise should be reasonable to divest the limit of the social cost burden, to assume the part that should bear. Therefore, it is urgently needed to study the accounting confirmation and measurement of the social cost of the enterprise, so as to establish the theoretical basis for the objective evaluation of the social benefits of the enterprise and learn the theory of social costs and practical experience from the western developed countries and take China's enterprises as the research object, this paper studies the contents and characteristics of social cost, and on this basis, it improves the basic theory of accounting recognition and measurement of social cost of enterprise in China, and then puts forward the policy suggestion of accounting reflection of social cost of enterprise in our country, and finally forms the conclusion.
\end{abstract}

Keywords-social responsibility; the social cost of enterprise; accounting confirmation; accounting measurement

\section{INTRODUCTION}

At the present stage, with the further deepening of economic globalization, the socialist market economy is full of vitality in China, and the social responsibility of enterprises is increasingly expanded. The social cost of enterprises will also be closely linked to the development of China's economy. Among them, it has become a new subject

*Fund: This research was financially supported by Fundamental Research Funds of Central Universities of Shaanxi Normal University; project number: 10SZYB26. to confirm and measure the social cost of enterprises.

However, there is still a lack of understanding on the accounting recognition and measurement of the social cost of enterprises in China, which is mainly reflected in the following aspects: first, enterprises lack the awareness of independent recognition and measurement of the social cost. At present our country enterprise in the basic no one in the social costs of accounting reports, which makes the information users could not convenient enterprise social cost accounting information, and at the same time also has a great influence to the establishment of the corporate image of, although have some businesses in its accounting recognition and measurement of added some information on social cost, but the content of the disclosure is limited; second, the overall goal of the enterprise is to achieve the "maximization of shareholder wealth", which leads to the accounting focus only on the micro-economic indicators, such as financial status, operating results and cash flow, etc. When people regard enterprises as a closed system to discuss the cost independently, the internal costs are only considered. At the same time, due to the pursuit of their own interests and the cruel and fierce market competition, enterprises have also caused some problems to the society, such as environmental pollution, unqualified product quality, food safety problems. These problems make us have to pay attention to the social cost of enterprises; third, the society and relevant government supervision institutions also agree that enterprises should take the initiative to assume social responsibilities. However, there is a lack of clear indicators to guide and measure how much social responsibility enterprises undertake; fourth, the research on the social cost of enterprises in China is still in the early stage and the exploration is not mature.

\section{AN OVERVIEW OF ACCOUNTING RECOGNITION AND MEASUREMENT OF CORPORATE SOCIAL COSTS}

At present, Chinese scholars mostly study the social cost of enterprises from a micro perspective. Professor Lin Wanxiang believes that the social cost of enterprises refers to the costs and costs paid by enterprises when they undertake the non-economic functions of their social functions [1]. It mainly includes: the enterprise's expenditure on social welfare such as medical care, housing, insurance and environmental protection that should be borne by the society. 
In addition, the social cost of enterprises has the following characteristics: microobjectivity, external economy, difficulty in measurement, involuntary, noneconomic function, incrementability, traceability and correlation.

Due to the characteristics of enterprise social cost, there are many problems in the process of accounting confirmation and accounting measurement, which are shown as follows:

\section{A. Traditional Accounting Assumption Can't Satisfy the Accounting Confirmation of Enterprise Social Cost}

Tax cost can be treated in accordance with the existing accounting confirmation, responsibility cost of worker pay and welfare, staff training expenses also has a standard accounting principles and methods, however, environment cost, quality benefit, public welfare cost accounting can't all confirmed now, first of all, these costs cannot meet the needs of the traditional accounting assumptions in the "currency" hypothesis, the company undertake social responsibility measures taken in the process of the social benefit or enterprise of technology, the cost of manpower and material resources have no way to directly measured in money and get accurate data to measure, If the traditional assumption of "monetary measurement" is not satisfied, accounting confirmation cannot be carried out and listed in the existing accounting report.

\section{B. Lack of Proper Accounting Recognition Principles}

At present, China's existing accounting recognition principles are: definability: quantifiable: relevance and reliability: importance; availability: on an accrual basis. These however can only be used as the existing accounting elements confirmation principle, for the content of social costs of quality cost, environmental cost, etc., due to their own characteristics, such as compulsory, so in the process of accounting confirmation clearly should also have other principles to constraints and norms of the enterprise, to ensure that enterprises can in accordance with the unified standards of accounting confirmation.

\section{Single Measurement Model}

When enterprises measure accounting elements, the units of measurement all choose currency, and the measurement attributes choose historical cost. However, with the development of economy and the change of times, the reliability advantage of simply using historical cost measurement for the social cost of enterprises is no longer available, and the measurement attribute of historical cost is faced with great challenges: (1) in the constantly changing environment, only the traditional historical cost measurement is no longer appropriate; for major decisions such as business investment, historical cost measurement is not the best choice. On the other hand, the accounting measurement object of enterprise social cost is quite wide, and its accounting measurement is more complex and fuzzy. In addition, the external environment changes a lot.

Monetary measures in traditional accounting are increasingly limited, inflexible and unitary. Therefore, the traditional accounting measurement model is mostly based on historical cost measurement attributes and monetary measurement. This single measurement model is obviously not applicable to the accounting measurement of enterprise social cost.

\section{There Is No Standard Disclosure Model for Measurement Results}

People mainly through the notes to the financial report, at present stage, the audit report to understand the accounting information of an enterprise, and once for accounting recognition and measurement of social costs, on the one hand, there is no way to get the full display in the disclosure way, on the other hand, even if the enterprise will be the cost of corporate social recognition and measurement results in the report disclosed or other way out, there is no unified and standard mode of the disclosure of limited, it is easy to cause the enterprise the way of disclosure, disclosure forms, people get to the measurement result is not very convenient, And the measurement results of the social cost of enterprises are compared and analyzed and the objective evaluation is given.

\section{SUGGESTIONS FOR IMPROVEMENT OF ACCOUNTING RECOGNITION AND MEASUREMENT OF ENTERPRISE SOCIAL COST}

\section{A. Improving Accounting Assumptions}

Accounting hypothesis is the cornerstone and basis of accounting confirmation and measurement. However, accounting hypothesis is not fixed, because the external environment changes, accounting hypothesis is also necessary to change to adapt to the environment. In addition to following the three assumptions of traditional accounting entity, continuous operation and accounting period, the accounting assumption of enterprise social cost should be improved appropriately according to the nature of enterprise social cost.

Fuzzy money measurement assumptions: social cost is very important to the development of enterprises. In order to avoid decision-making errors, users of accounting information need to collect information about social cost of enterprises. Therefore, the measurement index of social cost accounting should not only choose monetary measurement, but also choose indicators related to social cost to conduct more reasonable accounting and supervision. In this way, social costs can be regarded as a part of the enterprise cost system before they can be entered into the current financial report and disclosed to the public like other costs.

Environmental resource value hypothesis: environmental resources are valuable, that is, the value they contribute to current production and consumption, and the value they benefit from supporting current production or consumption activities. Traditional accounting does not take natural resource consumption and environmental losses into account. However, in order to calculate the social cost of enterprises, it is necessary to recognize the value of environmental resources, so as to avoid the waste of resources and environmental pollution accompanied by economic growth. 
Production sociality hypothesis: this hypothesis refers to the sociality of production and operation of enterprises, which determines that enterprises should undertake social responsibilities. Therefore, in the daily operation and decision-making process, enterprises should consider what kind of impact they will have on the society and whether they meet the expectations of the society on themselves.

\section{B. Improving the Accounting Recognition Principle of Enterprise Social Cost}

The accounting confirmation principle of enterprise social cost is the basic requirement and principle standard that the enterprise should follow when carrying out the accounting confirmation of social cost. It is not completely consistent with the recognition principle of traditional financial accounting. It follows several principles:

The principle of measurement weight variability: money is no longer the only unit of measurement, and the enterprise social cost can choose money or non-money in the unit of measurement, that is, according to the actual situation and the content of the enterprise social cost for appropriate selection. In addition, the traditional accounting measurement methods are no longer suitable for the accounting measurement of enterprise social cost. New accounting measurement methods can be found and different measurement methods can be selected according to different situations of enterprise social cost.

Consistency principle: the confirmation of corporate social costs should be consistent, that is, all enterprises should confirm their social costs continuously, rather than discontinuously and broken, and the contents confirmed by enterprises should also be consistent, rather than different contents confirmed by each enterprise.

Scientific principle: in the process of accounting confirmation of enterprise social cost, it is needed to follow the guidance of scientific theory and method, and the basic principles and standards of accounting.

Policy-based principles: the accounting confirmation of enterprise social cost must conform to the corresponding policies of the state and the requirements of The Times and the nation.

The principle of sociality: as an economic individual or a member of society in the market, enterprises show the characteristics that contribute to social progress in the process of operation, that is, the survival of individuals cannot be divorced from the society, and the confirmation of social costs of enterprises cannot be divorced from the needs of social reality.

The principle of objectivity: the confirmation of the social cost of an enterprise must be objective, not just based on the individual will, and must follow the objective facts. On this premise, the social cost of the enterprise should be confirmed fairly and objectively.

\section{Diversified Measurement Modes}

On the one hand, the five measurement attributes in accounting have their own advantages and disadvantages, so in the measurement process to achieve accounting goals, there are advantages and disadvantages. The social cost of an enterprise is different from other production costs of an enterprise, and there is no way to directly measure its external economic benefits, because most of the time it is not equal to the real costs and benefits of the enterprise. The audit of social cost is only the first step of accounting, and most of the accounting results have no direct market value, so the historical cost cannot be used as the only basis for valuation. Instead, various measurement attributes such as current cost, replacement cost or opportunity cost should be selected according to the situation at that time. However, in the implementation process, it is also necessary to combine the actual situation and accounting objects, and extend to other measurement attributes more relevant to decisionmaking.

On the other hand, corporate social costs can continue to be measured in monetary terms, but also need to be combined with physical, technical and other non-monetary units. For example, enterprise exhaust emissions can be measured by mass, volume and the content of toxic substances contained in it, while sewage emissions can be measured by physical quantity units such as concentration.

In short, a complete accounting measurement model, in addition to the measurement object is the object of measurement, but also contains measurement attributes and measurement unit two factors. The organic combination of different measurement attributes and units can form different measurement modes. At the present stage, enterprises' objective requirements for the accounting measurement of social costs are: mainly based on historical costs, and multiple measurement attributes coexist.

In addition, the social cost of enterprises has its particularity, and the difference in the existing accounting measurement methods of social cost of enterprises is relatively vague. However, its measurement characteristics determine the diversity of measurement methods and forms. You can only choose to adopt different measurement attributes according to the actual situation, and then refer to part of modern scientific measurement methods to estimate it, trying to make the results relatively accurate. In the accounting of social costs of enterprises, it is necessary to learn some measurement methods of accounting institutions, such as survey pricing method, third-party ruling method, defense expenditure method and opportunity cost method.

Similarly, the addition of these methods cannot guarantee the comprehensiveness of the measurement methods of the social cost of enterprises. People must keep pace with The Times, adopt the best measurement methods according to the characteristics of the social cost of enterprises and the actual situation, and continue to explore more suitable and targeted new measurement methods in practice. 


\section{Standardizing Disclosure Mode}

People can mainly set the disclosure mode of accounting measurement results of the following enterprises' social costs:

Informal way of reflection, which cannot rigidly adhere to a specific form but take a variety of expression methods, such as text description, tables, graphics and other informal forms to explain the role of business activities on the society and its own costs and costs.

Enterprise social cost is added in the existing reports or in the notes to the accounting subject to reflect, such as assets on the balance sheet of the party can disclose the enterprise to undertake environmental responsibility and the purchase of assets, the liabilities party disclosing trading in the past form of the need in the future enterprise social cost etc., in the income statement disclosure of corporate social individual pay cost related fees; For small and medium-sized listed companies, they can properly absorb the social costs of these enterprises of the new accounting items, one or several accounting items in the existing accounting statements listed. Thus in the accounting entries, accounting, the preparation of statements of this series of accounting workflow can refer to the current operating methods.

Both financial and non-financial information of independent report can be used to reflect the circumstances of the social costs of the enterprise: the enterprise may disclose the "corporate social impact report" and all kinds of comparative statements, such as "social target completion comparison table", "enterprise development trend" comparative statements, these statements as part of the accounting information disclosure of social costs. As for the listed companies whose conditions permit, they can try to compile independent accounting reports of the social costs of enterprises according to the social accounting items of enterprises [2].

\section{SUGGESTIONS FOR IMPROVING THE ACCOUNTING AND MEASUREMENT OF ENTERPRISE SOCIAL COST}

\section{A. Further Standardizing the Accounting Recognition and Measurement of Enterprise Social Costs}

The construction of accounting confirmation and measurement system of enterprise social cost can only fill in the blank of part of accounting theory in this aspect, and change the traditional accounting thinking mode to understand the problem of enterprise social cost, and then find the method for the problem, so that the enterprise social cost can be further reduced. But more importantly, it is necessary to further standardize enterprises in the process of their operations, so as to make them become the accounting treatment standard operations that listed companies must adopt when dealing with their social costs [3].

\section{B. Carrying out Accounting Confirmation and Measurement of Social Costs of Listed Companies}

Theory can only be tested and developed when it is applied to practice. So in regulated the social cost accounting recognition and measurement of enterprise, you have to apply this theory to real life, the first in the listed company to implement a set of way for enterprise social cost accounting, in the process of practice to find problems, and then discusses problems, solve problems, so as to further perfect enterprise social cost theory of accounting recognition and measurement, at the same time make it more suitable for the listed company of our country.

\section{Improving the Systems and Mechanisms for Controlling Social Costs of Enterprises}

Continuously improving the control mechanism of enterprise social cost system is very meaningful for the coordination of social and economic development: the company under the specification of the cost control system in the enterprise can make our own relationship on a micro level processing costs and benefits of behavior and attitude to get appropriate adjustment, further improve the quality of social and economic benefit, economic, and can effectively inhibit listed companies shirk and desire to escape the social costs.

\section{Making It More Difficult for Enterprises to Bear Social Costs Under the Rule of Law}

When managing the social cost of enterprises, you should pay attention to the international standards and establish a reasonable and standard evaluation system to control the social cost of enterprises. The best way is to emphasize the basic social costs that enterprises should bear in the general provisions of the company law, so as to bring the social costs of enterprises into the legal and standardized management system. In western developed countries, the company is evaluated comprehensively from three aspects of economy, society and environment. Among them, the economic index, as the basic evaluation index, has a relatively perfect and standard evaluation system, while the evaluation standard of enterprise social cost has not been standardized. Therefore, when strengthening company corporate social costs and legal system, it is possible to promote enterprises to search for more accurate recognition and measurement methods to measure their own corporate social costs to respond to the society and the government of the mandatory requirements, is the natural urge enterprises and society to further perfect the enterprise social cost accounting recognition and measurement system, the enterprise social cost accounting report also entered a new phase of development and level [4].

\section{CONCLUSION}

Establishing an accounting reflection system for corporate social costs, unifying the principles and methods of accounting confirmation and measurement of corporate social costs, and writing accounting reports on corporate social costs will become a research direction for accounting in the future.

\section{REFERENCES}

[1] Lin Wanxiang. Research status and future of China's cos management system - review and prospect of 30 years of reform 
and opening up $[\mathrm{J}]$. Journal of Shanghai Lixin Accounting College, 2009, 23(05): 3-10+97.

[2] Wang Xiaoping, Gao Huimin. Can smes fulfill their social responsibilities to reduce agency costs? [J]. Accounting Communications, 2018(30): 103-107.

[3] Cheng B, Ioannou I, Serafeim G . Corporate social responsibility and access to finance [J]. Strategic Management Journal, 2014, 35(1): 123.

[4] Dan Han, Xuemei Chen. Free cash flow, corporate social responsibility and enterprise value: an empirical analysis based on listed high-tech enterprises [A]. Advances in Social Science, Education and Humanities Research, Volume 176 [C]. 2018: 5. 